This is an early (post-review) version of:

"Visualizing the Mental City: The Exploration of Cultural and Subjective Topographies by Contemporary Performance Artists in Johannesburg", in: Research in African Literatures 44(2), pp.163-176. Special Issue: (In)Visibility in African Cultures. Guest Editors: Zoe Norridge, Charlotte Baker, Elleke Boehmer* DOI: $10.1353 /$ ral.2013.0032

\title{
Visualizing the Mental City: The Exploration of Cultural and Subjective Topographies by Contemporary Performance Artists in Johannesburg
}

\author{
ABSTRACT \\ Visibility and invisibility are fundamentally social categories that reflect and shape \\ social acknowledgement, acceptance and interaction. The relevance of inter-visibility \\ between urban dwellers as a mode of negotiating social tensions, racism or gender- \\ related aggressions becomes apparent in particular situations in public space. \\ Performance artists in Johannesburg such as Anthea Moys and Athi-Patra Ruga relate to \\ these situations by performing well-elaborated roles in specific social and territorial \\ settings. They bring somewhat invisible discourses, ideas, and notions of normativity \\ into social visibility. Johannesburg is a city marked by enormous political and social \\ shifts, accompanied by a strong persistence of normative ideas partly deriving from the \\ former segregationist politics during apartheid. In rendering these mental topographies \\ visible through their artistic practice, the performance artists offer moments of \\ renegotiation on diverse levels of social (in)visibility and unlock spaces for potentially \\ new modes of perception and public agency.
}




\section{(In)visibility in African Cities}

Recent social theory has emphasized the relevance of visibility as a profoundly social category that marks territorialities, that functions as a device for social and political control, and that constitutes notions of the public. Studies in urban African contexts have highlighted this fact, emphasizing that the field of the invisible, by contrast, is a field beyond official mechanisms of control. AbdouMaliq Simone (2002), for instance, addressed the social and at times also political power of informal urban practices that appear from and take place in the realm of the invisible, while Filip de Boeck (2002 and 2005) demonstrated the meaning of the "invisible city" as social imaginary that helps to cope with an urban context of infrastructural and political neglect, as is the case in Kinshasa. Invisibility, in both examples, means invisibility to those who are supposed to control and govern the city, or to those who adhere to a rationalist understanding of visibility as the only proof of truth or the real. For both authors, the invisible is socially as true as the visible. While the invisible often remains as invisible to the observer or researcher as it is to other social actors, he or she can learn more about it by analyzing discourses and interpreting practices related to this invisible world. Hence, the invisible is as much part of social reality as the visible, but it often escapes our attention, because it is not as obvious as the visible world, and, relatedly, because it often is mediated by discourses, images or acts that, themselves, first need to be analyzed and understood.

The invisible does not belong to an "other" world; it is not the opposite of everyday life but rather forms an intrinsic part of it. Andrea Mubi Brighenti (2010) convincingly demonstrated how the interplay of the visible and the invisible belongs to everyday practices in society at large and to political and economic powers in particular. As he emphasizes, (in)visibility is a question of inter-visibility and therefore is a deeply 
social and relational phenomenon: "The relationship of looking at each other constitutes the site of mutual recognition, misrecognition or denial of recognition of the other--in short, the site where we constitute ourselves as "subjects"” (Brighenti 27). The (in)visible is intrinsically part of the social and, according to Brighenti, it closely interrelates with territoriality. Visibility is conceived as an "element" of the social, in which territorial thresholds are drawn, inscribed and projected (Brighenti 38). The field of visibility therefore is relational, strategic and processual, or "evental" (Brighenti 32; 37-39), that is, marked by the characteristic of taking place in particular moments. According to Brighenti, the field of visibility presents itself in various consensual or contested normative regimes that, as mentioned above, decide upon the "truth" in social perception. Visibility thus has a normative dimension and whoever or whatever is invisible or hyper-visible falls out of this frame. According to Brighenti, resistance unfolds precisely in these two realms of the invisible or the supra-visible.

Normativity, too, exists in great measure in discourses beyond the directly visible; there where projections and assumptions take place just because of the social invisibility between particular individuals or social groups. This aspect of (in)visibility has received little consideration by Brighenti but plays an important role in African (and other) cities. The invisible is the realm where people tend to inscribe meaning into events and processes that evade rational or logic explication. Its presence is strong in places where the population is exposed to the arbitrariness of governments or global economies, where legal structures do not correspond with social practices, and where quick and unpredictable social, cultural, economic and political changes take place.

Segregated societies in particular develop certain imaginaries and prejudices about "other" parts of the population that often escape visibility. Such social invisibility 
may have diverse reasons like segregated housing and education policies, as during apartheid, but also high crime rates that disseminate fear from unfamiliar or foreign people, and suspicion toward unknown ways of living or toward acts that apparently oppose customs or other normative values. Especially in cities with large social disparities like in the Global South, where diverse cultures and value systems converge, we observe a disparity between what people know from the visible and what they know from the invisible world; between knowledge about some individuals on the one hand, and suppositions and rumors about them and their kin on the other.

Particularly in South Africa where apartheid segregated black and white life in a manner that enabled the white population to forget about the living conditions of the black population, such disparities based on the divergence between what people know through experience and what they assume by rumor or media reports still have a strong hold. Although many residents from all parts of Johannesburg and Soweto have extended their trajectories into parts of the city they had not known before, for many, new enclaves have developed. These enclaves either serve as their own isolated home like the gated communities in the north (see Murray and Bremner) or they have turned from a familiar place into a no-go-zone or an assumed ghetto like the inner city neighborhoods of Hillbrow and Berea where the majority of the population consists of migrants who come from other African countries, like Zimbabwe, Mozambique, the Congos, or Nigeria (see Morris, Landau, Simone). While racial segregation has declined (but barely disappeared), other forms of segregation are evolving along the line of class difference, nationality, or even gender. Although the new democratic legislation has abolished segregationist politics, they still exist socially among South African nationals and often operate against foreigners. They are expressed in the fears and prejudices that 
accompany discourses about unknown or unfamiliar terrain. Much of this fear derives from the late 1990s when Johannesburg suffered an extremely high crime rate, but also from former apartheid politics in which people were confined by law to particular territorial areas, to facilities designated for either black or white persons, and to other restrictions associated with the racist politics of apartheid (see Beavon). While Whites certainly were privileged in this system, today, many suffer a continuation of the paranoia of that time, unable to free themselves from negative imaginaries of black South Africans, while many of the latter have developed a similar attitude towards Whites or African foreigners.

\section{Mapping the Social Meaning of The (In)visible through Performance}

Artists are especially attentive observers of such social mental maps and of the continuing dissociation of parts of South Africa's population in spite of its almost twenty-year-old democracy. Particularly the younger generation that enjoyed school and/or university in the new South Africa often relate to these social gulfs, question them, and dig deeper into the normative ideas lying behind the invisibility or ignorance taking place between diverse social groups in the urban space.

In the following, I will discuss the practice of two South African performance artists who question and challenge the pertaining territoriality of social segregation and the normative ideas informing them, precisely by relating to notions of visibility and invisibility as social practices. When I met Anthea Moys and Athi-Patra Ruga in 2008, both artists lived in Johannesburg--a city that has undergone the perhaps most tangible post-apartheid change in whole South Africa. The population patterns of the inner city and parts of the suburbs have literally changed colors, while certain prejudices, fears and 
a sense of "haunting" (Murray; Farber/Buys) are continuing and some suburbs have remained more or less the same for decades.

Moys and Ruga were particularly interested in the inner city of Johannesburg that had been heavily neglected during the 1990s and only started to recover in the early 2000s. While economic power-houses left the city in favor of the northern suburbs like Sandton, workers and labor-seeking people from townships, the rural areas or other African countries moved into the inner city, turning it from a "white" residential area first to a "greying" area in the $1980 \mathrm{~s}^{1}$ and then into an almost exclusively "black" area. Poverty, a nearly bankrupt city, unemployment and other factors contributed to a rising crime rate that would mark the reputation of Johannesburg for the next decades. Even today, after significant interventions by the municipality, prejudices about the dangers of the city persist, although the city image was significantly ameliorated through the peaceful and incident-free hosting of the Soccer World Cup in 2010.

The artists are aware of these entrenched prejudices within the city, but also of a blur, a relativization, and a constant reorganization of spatial reality. They are familiar with the presuppositions of many people, their fears and their habits which result in the very way of how people do--or do not--move in the inner city of Johannesburg. Borrowing a high social awareness from recent South African history, performance artists in Johannesburg tend to engage with factual and perceived notions of what and how the city is or is supposed to be. They explore the legal as well as illegal, formal and informal urban space either by integrating their one-man-performances into the streets of Johannesburg or by engaging in specific interactions with the diverse communities. Thus, they explicitly or implicitly deal with questions of mental topographies, attributions of space, social fears, and practices of inclusion and exclusion--all 
phenomena which become at times visible, but more often than not exist in the invisible realm, as mental images, personal nostalgia, fear of the foreigner and a love to certain places charged with memory. With their art, performance artists manage to make visible--at least to a certain extent--not only the realities in which such mental images are embedded, but also representations of rather abstract, invisible feelings and imaginaries. On the basis of the work of Athi-Patra Ruga and Anthea Moys this paper asks on what assumptions the performances are founded, and with which strategies they explore the interrelationship of the visible, the invisible, and the discursive fields of contemporary urban topographies.

\section{Athi-Patra Ruga: Shaping Counter-Normative Space in Hyper-Visibility}

Athi-Patra Ruga (born 1984 in Umtata, Eastern Cape) experienced the major part of his school education in the new democracy of South Africa. After his Matric at the age of 17, Ruga moved to Johannesburg where he studied for the Honors Diploma in Fashion History and Design at the Gordon Flack Davison Design Academy. It is in Johannesburg and during his residencies abroad that he established a name as a performance artist, a path that he had chosen after he realized that fashion alone did not really make him happy. Although he maintained his label Just Nje and continued to be active in the fashion design world of Johannesburg, he increasingly dedicated his time to performance and visual arts. His performances take place in diverse sites such as clubs, private homes, exhibition spaces, or in the urban public space. ${ }^{2}$

While his performance pieces often have a narrative character, some of them likewise raise questions about the public space, particularly in Johannesburg and Cape Town. Ruga maps the city along the borders of fashion as a body architecture and a 
signifier of social subjectivities in relation to urban spaces. Fashion, body language, and the places where he chooses to perform, constitute a subjective publicness or a public subjectivity; a clash between legal and individual freedoms and social norms. Ruga is interested in the public space as a place of interaction and confrontation, making use of the intervisibility Brighenti mentioned as fundamental condition for any kind of social visibility and acknowledgement. Exploring these social territories, Ruga is very aware of the heterogeneity of potential audiences. ${ }^{3}$ Knowing that nobody traverses a city without a certain idea of what is "normal" or "common sense" and without fearing the encounter of what is apparently senseless, dangerous or deadly, Ruga explores the diverse levels of how you can act--but also of how you will be perceived--in the streets of Johannesburg or Cape Town. Parameters such as gender, ways of moving, dressing and behavior, race and ethnicity, paths chosen and encounters sought or avoided aggregate to distinct ways of perception and reactions. To know, or at least assume, in which neighborhoods your appearance may be welcome and in which not, can be, at times, life-saving.

In a series of performances conducted in 2008, Athi-Patra Ruga performed the character of Beiruth. The name refers to the city of Beirut as a contested city, but also Ruth in the book of Ruth. Among other motivations to produce this work, the artist mentioned the xenophobic attacks which took place in May 2008 (called 5/11 in the vernacular) in townships all over South Africa as well as in the inner city of Johannesburg (Siegenthaler/Ruga). The performances as well as the name of Beiruth allude to the autonomy of a city or state as well as to the autonomy of the (foreign) body moving in it. ${ }^{4}$

One performance in this series, ... after he Left (2008), took place in the Cape Town Central taxi rank. Like all taxi ranks in the major cities of South Africa, it is the 
heart and core of the urban economy and life; the taxi rank is the important central station for all commuters who cannot afford the car or prefer the minibus to the train. In this sense, it is a highly public space. However, this public space has adopted diverse meanings in South African society. Car-drivers and upper class people have barely ever seen the station from inside because they have their own car. For them, a taxi rank is a loud, crowded, messy and sometimes also filthy place where those gather who cannot afford anything else. For women, it may be a place of sexual harassment--a perception that is repeatedly confirmed by sexual and gender-related assaults on young women who wear short skirts or dress in a way considered inappropriate (O'Toole and Molatlhwa). ${ }^{5}$

In such a taxi rank, Beiruth catches a night taxi to the township called Atlantis--a real township which is far from any mythical utopia associated with the lost continent. Atlantis, situated about 40 kilometers out of Cape Town, is marked by isolation, poverty, unemployment, drug abuse, and--according to Ruga's information--child rape and child murder. ${ }^{6}$ At first, Athi-Patra Ruga alias Beiruth walks through the minibus station, waiting for the taxi. S/he ${ }^{7}$ is dressed in an eye-catching attire: black-and-white net stockings and red high heels are topped by a skin-tight red wrestling suit showing the bare male chest, arms and shoulders. A wide black belt presses Beiruth's waist into a female shape. Ruga's head is covered by a lamp shade which obstructs his view while Beiruth is striding around in a very slow, sexy and feminine way. Beiruth's movements lend her a feminine or androgynous touch, whereas the leather wristband alludes to camp, punk, or dominance. In her entire appearance, Beiruth thoroughly exposes herself both as an alien and as a sexual being.

The unedited performance video film shows reactions of some people present at the site of the performance. For instance, it shows us a young woman who flirts with 
Beiruth and looks into the camera, showing off her own female curves. She appears to approve of the performance and joins it by offering herself to the camera. However, there is also a man who appears to develop an aggression, and after looking at Beiruth as sheepishly as his colleagues, he nudges the performer with his shoulder. He appears to share existing prejudices against cross-dressing people who often are identified with homo- or transsexuality. Although South Africa has, since 1997, one of the most progressive constitutions in the world, including legalization of same-sex relationships and marriage (since 2006), in social perception, homosexuality is still often a taboo, considered to be abnormal, perverted, or "un-African" (Tucker). ${ }^{8}$ The man's reaction against Beiruth indeed is reminiscent of the aggression of those taxi drivers who assaulted a young woman some months before. ${ }^{9}$

At the end of the performance, Beiruth poses in the arriving taxi and waits for fellow travellers welcome to join. Although the film crew paid the minibus-driver fully and other passengers therefore would have travelled for free, not one person followed Beiruth.

The audience, which in this case is an involuntary and random audience, witnesses Beiruth's hypervisibility which responds to the often invisible but very present discourses of homophobia and misogyny, and they partly feel encouraged or provoked to take action against or in support of the performer. It is these mechanisms, happening in a taxi station, that Ruga brings to light through the performance itself, but also through the video documentation which later is shown in an art gallery context. The visual codes in his attire and behavior are associated with gay culture, with the effect that he as an individual is considered to be gay. Ruga's appearance is de-coded as belonging to homosexual culture that in turn clashes with prevailing hetero-normative and often 
misogynist attitudes. While Ruga consciously alludes to instances of sexual or other assaults marked by social intolerance, his art figure Beiruth appears to ignore such normative social imaginations. S/he appears to act in total naivety, like an alien, who either is not aware of or even takes pride in being different.

With this performance, Ruga made discourses visible by provoking reaction in the audience, and thus made clear that social acceptance--in spite of the extremely progressive constitution--is still lacking and those who transgress the social norms risk being discriminated against in public spaces. It is the common sense (Geertz; Giddens 334-343)--or rather its contestation resulting from the constantly growing plurality of cultures in the city--that Ruga reflects in his work precisely by acting as an alien.

Ruga's strong awareness of how the body, its appearance and movements are signifiers of cultural and social codes which on the one hand are influenced by the space surrounding them, but on the other hand also have the force, at times, to reshape places and space, challenge and replace to a certain extent the constructed space of urban architecture. The notion of counterpenetration, which Ruga uses for another performance series ${ }^{10}$, perhaps best speaks of Rugas artistic practice: it challenges territorial and social properties through a hyper-visible intrusion into spaces defined by a supposedly uncontested common sense that prevails within a visible urban environment.

\section{Anthea Moys: Connecting and Familiarizing through Place-making}

Anthea Moys (born 1980 in Johannesburg) continued her early dance passion at the University of the Witwatersrand (Wits), attending courses in dance, drama and fine arts. She did her BA in Fine Arts and then worked for her MA at the Master of Arts in the Public Sphere program at Ecole Cantonale d'Art du Valais (ECAV) in Sierre 
(Switzerland) for a year, followed by the final year and an MA degree in Performing Arts at Wits University. Her MA thesis, submitted in 2008, dealt with the notion of play in public space. She explored and still explores this field in practice: the notion of play occupies a prominent role in her performances. For instance, she took courses at a boxing club in Hillbrow and organized a boxing game event in which she invited friends from Johannesburg's suburbs to join her in a playful tournament with boxers living in Hillbrow. On other occasions, she organized enjoyable trails for inner city youth to help them become familiar with the neighborhood. The majority of her performances show similarities to happenings and are often community-oriented. Moys takes the role of a temporary playful leader, directing diverse groups into a space which is charged and unknown to them, to create a shared, communal space--even if it is only for a moment. For this, she often uses places which should have a communal function such as parks, sport clubs or cultural institutions. Although they are considered "public", many of these spaces have a long history of exclusionary practices from apartheid to the present day. Moys tries to overcome this partly self-imposed exclusion by bringing certain target groups into areas that they normally ignore, avoid or even fear for different reasons, mostly because of crime, neglect or simply because of habit and everyday routine. She does this predominantly with interactive interventions.

However, for some performances, she decides to play a role as a main actor in which an audience is involved but not necessarily a full co-actor in the process, as is the case with Nessun Dorma (2008). Reducing the communicative aspect of her work and instead intensifying the symbolic act in this performance, she did not interact directly with her human surroundings but rather with the spatial context of Joubert Park, one of Johannesburg's larger parks, adjoining the Johannesburg Art Gallery. Until recently, it 
was considered to be specially contested; a no-go-zone situated in downtown Johannesburg because of drug dealing, prostitution and robberies that took place there. It is also a symptomatic place for the ongoing divisions in South African society: the museum had been rigidly fenced off towards the park for a long time and only in recent years started to open the gates at daytime. ${ }^{11}$

Moys performed Nessun Dorma in the zone between this park and the art gallery. She placed a bed into this zone, well equipped with cushions and a duvet. The setting corresponded more or less to the room where she was actually sleeping at that time, except some details that had to be adapted through the transplantation from a closed space into open space, for instance by replacing the night lamp with a head torch. In her description of the work, the artist says:

"Sleeping in a bed of roses fenced off from the gallery (and the rest of the area), in one of the most dangerous parks in the city (and maybe the world), I enact what I do each night in my own bedroom. I am guarded by four CSS Tactical Security guards while I read the wonderfully optimistic book 'Don't Panic: A Book written by South Africans for South Africans', which reminds me to keep 'hope' alive within me, before I doze off into dreamland. On my left side I have The Faber Book of Utopias. Before I go to sleep, two opera singers sing the [sic] Puccini's aria, Nessun Dorma, the English edition of which is translated as 'None Shall Sleep Tonight'. The gates to the park, which had not been opened in over five years, were opened to the public that night and audience members could enter the park." 12 
Moys joins two extremely separate spaces: The no-go-zone of Joubert Park and the highly secured home of wealthy people in the northern suburbs who hire private security companies to protect themselves. As Moys puts it, "[t]his [fortification] is not eccentric or unusual. This is what we do. And at night, when we go to sleep so well 'secured', we are, most of us, still afraid." 13

This constant state of alert seems to be the link between these diverging spaces-an open inner city park and a fortified suburban house. Moys points towards these similarities and differences when she transplants a northern suburb-style bed into Joubert Park. $^{14}$

By performing this symbolic encounter, Moys reflects explicitly on the notion of visibility, witnessing, and, related to this, social witnessing and participation. While the suburban residents remain invisible to the inhabitants of the inner city and the park in particular, the park and its real dwellers also remain invisible to the suburbanites who avoid entering the assumed no-go-zone. There is a mutual invisibility through lacking intervisibility that furthers mistrust and fear. By transplanting her bed into the park, Moys turns the fortified private spaces public, but also literally illuminates a park that has remained or become a black spot in the perception of many residents of Johannesburg.

The fact, that the museum opened its gates that night and the audience attended a two-hour-performance that nobody would have imagined in this park, is crucial in this context and must be considered part of the performance. The act of "releasing" a group of people into the park who normally never would even approach it, is not only a proof of trust in the security guards, but also in the possibility that irritations in habits of spatial use can make a place safer. In a way, the visitors were co-guards too. But also 
vice versa, the extreme visibility of Moys, her exposure, illuminated by light, guaranteed to those attending that something extraordinary is happening, brightening up the usually dark and dangerous park and thus interrupting not only the visitors' habitual perception of it, but perhaps also the perception of its everyday nocturnal users. The "obscure", the powers and persons feared in the park, have either to join the group or withdraw even further into the dark. By placing herself in a highly visible manner in the park, accompanied by highly audible and illuminated opera singers, she claimed a visibility in the park that had not existed for two decades, during which time Joubert Park had transformed from an almost exclusively white-dominated space to a space used by exclusively black urban poor, informal traders, sex workers, drug dealers and other individuals considered dangerous.

In the same act, however, she also was able, to a certain degree, to show to the art audience living mainly in the northern, historically white suburbs, what Joubert Park is like at night. They experienced a part of it directly rather than relying on rumors and assumptions. By arranging this situation, Moys aimed at creating an entry point to territorial familiarity for the audience. At the same time, she also communicated to those normally using the park that there are other stakeholders, too, and that these stakteholders have not entirely disappeared in the suburbs but tend to re-venture into the city.

With the performance of Nessun Dorma it became clear, that not only poor or excluded groups within the inner city do have a marginal status of perception, but also residents in the wealthy northern suburbs. It confirms Brighenti's view that visibility and public space depend essentially on social inter-visibility. While the performance was not as interactive as most of Moys's other work and it therefore perhaps is less effective 
socially, it pointed trenchantly to the very mechanisms of visibility and obscurity in a society marked by striking social and economic segregation, prejudices and mistrust.

\section{Conclusion: Performing (In)Visibilities and Discourses}

Summarizing the analysis of the performances of Anthea Moys and Athi-Patra Ruga, it becomes clear that both artists refer to and adopt several registers of (in)visibility in their practice. I propose to distinguish four categories of (in)visibility taking place during the performances.

The first category is the social (in)visibility of interaction and marginalization. This (in)visibility is grounded in the actual everyday activities of urban residents; places and people they encounter and know, and other places which are unknown or taboo to them. Interaction establishes inter-visibility while the lack thereof increases the probability that particular social individuals or groups are excluded and marginalized. The artists observe this category of (in)visibility long before their actual performance, mainly through their own experience of particular urban areas. (In)visibility of interaction and marginalization can be captured by analyzing whether people interact, for what reasons, and in what manner. The renunciation of interaction is part of this category, too. People living illegally in Johannesburg might be keen to remain as oblique as possible, fearing persecution by the immigration authorities. Others might fear xenophobic, homophobic or otherwise motivated aggression. ${ }^{15}$

This first category is tightly interrelated with the second category that I call secondary (in)visibilities and discourses. Secondary (in)visibilities and discourses are more difficult to trace, because they are often incorporated in discourses and reveal their meaning only there. This category explores ideas, discourses and imaginaries that evolve 
from superficial city experience or the lack thereof. As an example, we may think of the "broken window theory" (Wilson/Kelling): Just because a certain area shows infrastructural decay, residents as well as urban policy makers conclude that it attracts or already is home to crime. Crime itself is a rather invisible threat associated with criminal individuals whom average citizens try to avoid. The knowledge about who exactly lives in such a neglected building therefore often is a discursive or gossip knowledge; the idea that it must be a criminal group mounts to a form of local knowledge evolving from assumptions about a place that one barely would visit and thus actually never has seen. The Joubert Park is such a place. While it is very familiar to its users who also share social visibility with other park users, it is an unknown territory to the average museum audience although they can glance at it through the museum fence. This short and superficial gaze mostly tries to avoid direct interaction with the people occupying the park who are not only physically but also socially and discursively separated from the museum visitor. Moys refers to these secondary invisibilities by performing her piece in an area that is charged by such prejudices that evolved, not least, by discourse, and not by direct experience. Most of the museum-goers never experienced crime in Joubert Park but heard of it. Similarly, Ruga traces homophobic and misogynist discourses by particular but in fact quite superficial means of comportment and dressing.

Both artists elaborate precisely on the interplay between the categories of social and secondary (in)visibility. Therefore, I propose a third category that asks how (in)visibility is reflected in performance art. The performers have particular strategies to be seen or unseen. Their bodily appearance and action relate to both, direct social interaction as well as secondary (in)visibilities. Thereby, they display a high awareness for place on the one hand and audience on the other. They consciously choose places 
and address potential audiences for their performance. While Moys opted for her own hyper-visibility in a park that is unfamiliar to the invited audience, Ruga opted for a taxi rank that is highly familiar to the random audience that happened to experience his intervention. While Moys's audience thus sustained her visibility in the dark park, Ruga rather was exposed to acts of inclusion or exclusion, being either welcomed by the young lady or chased away by the man nudging him. Both artists used the means of hyper-visibility through either Ruga's attire or Moys's illuminated scenery, but they targeted different audiences.

However, both force the audience into an engagement--be it an interaction among each other or just a reflection of the own attitude or relation to others. The performative act becomes a moment of visibility or visualization of the artist, but also a discovery of invisible social knowledge, assumptions or prejudices. The artists visualize the invisible through the explicit and ephemeral act of becoming and being visible; through the act of claiming visibility.

Moys and Ruga manage to reflect the linkages between the different categories of (in)visibility. By means of a performed hyper-visibility, penetration and interaction, the artists firstly direct the imageries of the city from its visible spaces and inhabitants towards the invisible discourses and assumed common sense. Thus, secondly, they show how socially constructed meanings, fears and prejudices are linked to these places and their very (in)visibility. Thirdly, by interlinking the social and discursive (in)visibilities of the city, they redirect the attention towards a potential of new visibilities and imagination.

Following these three categories, one might sketch a fourth one that considers the actual and factual (in)visibility of the performer to her or his audience, thus readopting 
the perspective of the sociological observer who asks in what relation the artists stand to their publics in the moment of their performance. It is a deeply empirical question because it must be observed on place and in the aftermath of the event in a similar manner like the first category. It asks what effect the performance has de facto, beyond the purposes of the artists. It reflects the experience of the audience and the consequences for its future spatial practices in the urban realm. This question only can be answered when the event is actively observed and documented, and when the researcher has access to the often unfamiliar audience in order to collect qualitative data in interviews, surveys or through observation. This last category unfortunately is mostly neglected in the analysis of art works because it is deeply sociological. However, if we assume that performance art in public space and its aesthetics have cultural, social or political effects, it is crucial to enquire the perception and experience of the invited as well as the casual audience.

Of course, these proposed categories are conceptual categories which in reality are much more diverse and flexible. Even the idea of invisibility as an opposition to visibility is in fact just a model. From an empirical point of view, the categories presented here do intermingle. They are barely separable and thus also provide for the complexity of the mappings and images of the city based on visible and invisible social realities and imaginaries. However, they help as an analytical tool for the discussion and analysis of performance in public space, as a way to trace the mental topographies of the city and its inhabitants.

\section{NOTES}


${ }^{1}$ Grey Areas, or the process of "greying", stand for general shifts in the residential pattern in South African cities from the mid-1970s on. It describes "the movement of black people as genuine tenants into formerly whites-only areas" (Beavon 213).

${ }^{2}$ For more on Ruga, see Ruga and Siegenthaler/Ruga.

${ }^{3}$ I speak of publics or audiences in the plural form as proposed by Kurt Iveson (2007) because there are socially, culturally and territorially diverse publics and audiences. For a more detailed discussion of the relation of Ruga's performance work to the public space, see Siegenthaler.

${ }^{4}$ After her husband's death, Ruth from Moab accompanies her mother-in-law to Israel although she is regarded there as a foreigner and her rights are limited. Ruga compares her situation with that of Zimbabwean and other immigrants in South Africa, but also with the submissive gender role expected from women in many cultural contexts of contemporary South Africa.

${ }^{5}$ See also the article "Abusive, Sexist Taxi Drivers Criticised”, Independent Online, 28 Feb. 2008 (http://www.iol.co.za/news/south-africa/abusive-sexist-taxi-drivers-criticised1.391199\#.UPIJHXfx1I0; 18 Jan. 2013).

${ }^{6}$ Atlantis was founded by the apartheid government in the late 1970s for "coloureds" as the apartheid terminology defined people of mixed race. Like many other townships situated in a harsh landscape and isolated from economic opportunities, it suffers social isolation, poverty, unemployment, high crime rates, drug abuse and domestic violence (see also Clayton).

${ }^{7}$ It is unclear whether Beiruth is a male or a female. While the artist talked about a "he" in his interview with David Brodie (Brodie/Ruga) it was a "she" in the conversation with 
me (Siegenthaler/Ruga). This ambivalence is peculiar to the trickster-like character of Beiruth whom I prefer to look at as an intersexual being. In the following, I will therefore refer to Beiruth as a s/he.

${ }^{8}$ Frequently, it is also related to witchcraft and therefore becomes an issue concerning an entire social group because a person who is bewitched is feared to do harm to his or her community. This social stigma is encountered in church communities, schools, and taxi ranks alike.

${ }^{9}$ See O’Toole, Molatlhwa, and footnote 5.

${ }^{10}$ Even I Exist in Embo: Jaundiced Tales of Counter-Penetration; a performance series conducted in different places in Switzerland in 2007.

${ }^{11}$ Much has been told and written about this unique constellation. The museum, a symbolic place of white power and colonialism since the early 20th century, found itself in the 1990s in direct neighbourhood with homeless people, prostitutes, drug dealers and other socially disadvantaged persons. The realities of a post-apartheid society literally knocked at the door of a building into which for a long time no black person would have made a step. However, fortunately the museum started to open its gates for interested people from the neighbourhood, and especially during the directorship (2004-2008) of Clive Kellner, many projects were undertaken to lower the virtual walls between the museum and its surroundings.

12 This quotation is taken from a previous version of Anthea Moys's website (http://www.antheamoys.co.za; 27 Aug. 2010). Currently it can be found with the online documentation of the performance (www.youtube.com/watch?v=cRNF8TvjhSg; 18 Jan. 2013). 
${ }^{13}$ Quotation taken from a previous version of Anthea Moys's website (http://www.antheamoys.co.za; 27 Aug. 2010).

${ }^{14}$ Interestingly, the performance was re-done at the Dray Walk Gallery in London in November 2008. This totally different setting in an exhibition space reduced the poignancy of the original act. On the other hand, it may have opened up new aspects on the performance that had remained ignored within the Joubert Park setting.

${ }^{15}$ AbdouMaliq Simone has shown insightfully how certain immigrant groups in Hillbrow either demonstrate their presence publicly in the streets or prefer to remain unrecognized for business or other reasons (Simone 412-414).

\section{WORKS CITED}

Beavon, Keith. Johannesburg. The Making and Shaping of the City. Pretoria: University of South Africa Press, 2004.

Bourdieu, Pierre. Outline of a Theory of Practice. Cambridge: Cambridge University Press, 1977.

Bremner, Lindsay. 'Closure, Simulation, and 'Making Do' in the Contemporary Johannesburg Landscape." Under Siege: Four African Cities: Freetown, Johannesburg, Kinshasa, Lagos. Ed. Okwui Enwezor et al. Documenta 11, platform 4. Ostfildern: Hatje Cantz, 2002. 153-172.

Bremner, Lindsay. Johannesburg. One City Colliding Wolds. Johannesburg: STE Publishers, 2004.

Brighenti, Andrea Mubi. Visibility in Social Theory and Social Research. London: Palgrave/Macmillan, 2010. 
Brodie, David and Athi-Patra Ruga. Interview. Unpublished, 2008. For a version of the interview in German language, see: <http://www.hebbel-amufer.de/media/INTERVIEW\%20ATHI\%20PATRA\%20RUGA.pdf> (3 Jan. 2012).

Clayton, Jonathon. "Toxic Hit that is Fuelling Crime and Violence in the Townships." The Times 30 July 2007.

<http://timesonline.co.uk/tol/news/world/africa/article2163680.ece> (18 Jan. 2013).

De Boeck, Filip. "Kinshasa. Tales of the 'Invisible City' and the Second World." Under Siege: Four African Cities: Freetown, Johannesburg, Kinshasa, Lagos. Ed. Okwui Enwezor et al. Documenta 11, platform 4. Ostfildern: Hatje Cantz, 2002. 243-286

--- and Marie-Françoise Plissart: Kinshasa. Récits de la Ville Invisible, transl. JeanPierre Jacquemin. Bruxelles: Renaissance du Livre, 2005.

Farber, Leora and Anthea Buys. "Die Unterwelt, die Oberwelt und das Zwischenreich. Eine Hantologie der Stadt Johannesburg." Afropolis: Stadt--Medien--Kunst. Ed. Kerstin Pinther, Larissa Förster and Christian Hanussek. Köln: Walther König, 2010. 292-301.

Geertz, Clifford. "Common Sense as a Cultural System.” Idem: Local Knowledge. New York, 1983. 73-93.

Iveson, Kurt. Publics and the City. Oxford: Blackwell, 2007. 
Landau, Loren B., ed.: Forced Migrants in the New Johannesburg: Towards a Local Government Response. Johannesburg: Forced Migration Studies Programme, 2004.

Mitchell, Don. The Right to the City. Social Justice and the Fight for Public Space. New York/London: The Guilford Press, 2003.

Molatlhwa, Olebogeng. "Women in Miniskirt Attacked at Taxi Rank." Sowetan 3 Jan. 2012

< http://www.sowetanlive.co.za/news/2012/01/03/women-in-miniskirt-attacked$\underline{\text { at-taxi-rank> }}$ (18 Jan. 2013).

Morris, Alan. Bleakness \& Light. Inner-City Transition in Hillbrow, Johannesburg. Johannesburg: Witwatersrand University Press, 1999.

Murray, Martin J. Taming the Disorderly City. The Spatial Landscape of Johannesburg after Apartheid. Ithaca/London: Cornell University Press, 2008.

Neocosmos, Michael. From 'F oreign Natives' to 'Native F oreigners'. Explaining Xenophobia in Post-apartheid South Africa. Dakar: CODESRIA, 2006.

Nuttall, Sarah and Achille Mbembe. Johannesburg. The Elusive Metropolis. Durham and London: Duke University Press, 2008.

O'Toole, Sean. "Don't Show That! Contemporary African Artists Respond to Prejudice and Homophobia." frieze 133, Sept 2010.

<http://www.frieze.com/issue/article/dont-show-that/> (18 Jan. 2013).

Ruga, Athi-Patra, ed. Athi-Patra Ruga, The Works 2006-2009. Cape Town:

Whatiftheworld, 2009. 
Siegenthaler, Fiona. "Athi-Patra Ruga's Performances. Showing the Invisible Side of Public Space.” Athi-Patra Ruga, The Works 2006-2009. Ed. Athi-Patra Ruga. Cape Town: Whatiftheworld 2009. 7-15.

Siegenthaler, Fiona, and Athi-Patra Ruga. Interview. Johannesburg: 16 July 2008 (unpublished).

Simone, AbdouMaliq. "The Visible and the Invisible: Remaking Cities in Africa." Under Siege: Four African Cities: Freetown, Johannesburg, Kinshasa, Lagos. Ed. Okwui Enwezor et al. Documenta 11, platform 4. Ostfildern: Hatje Cantz, 2002. 23-44.

---. "People as Infrastructure: Intersecting Fragments in Johannesburg." Public Culture 16.3 (2004). 407-429.

Tonkiss, Fran. Space, the City and Social Theory. Social Relations and Urban Forms. Cambridge: Politi Press, 2005.

Tucker, Andrew. Queer Visibilities. Space, Identity and Interaction in Cape Town. Oxford: Wiley-Blackwell, 2009.

Wilson, James and George Kelling. "Broken Windows: The Police and Neighborhood Safety." Atlantic Monthly, 269.3 (1982). 29-38. 